\title{
Identifying uncertainties in Arctic climate change projections
}

\author{
Daniel L. R. Hodson · Sarah P. E. Keeley • \\ Alex West · Jeff Ridley $\cdot$ Ed Hawkins • \\ Helene T. Hewitt
}

Received: 6 March 2012/ Accepted: 27 August 2012/Published online: 18 September 2012

(c) The Author(s) 2012. This article is published with open access at Springerlink.com

\begin{abstract}
Wide ranging climate changes are expected in the Arctic by the end of the 21 st century, but projections of the size of these changes vary widely across current global climate models. This variation represents a large source of uncertainty in our understanding of the evolution of Arctic climate. Here we systematically quantify and assess the model uncertainty in Arctic climate changes in two $\mathrm{CO}_{2}$ doubling experiments: a multimodel ensemble (CMIP3) and an ensemble constructed using a single model (HadCM3) with multiple parameter perturbations (THCQUMP). These two ensembles allow us to assess the contribution that both structural and parameter variations across models make to the total uncertainty and to begin to attribute sources of uncertainty in projected changes. We find that parameter uncertainty is an major source of uncertainty in certain aspects of Arctic climate. But also that uncertainties in the mean climate state in the 20th century, most notably in the northward Atlantic ocean heat transport and Arctic sea ice volume, are a significant source of uncertainty for projections of future Arctic change. We suggest that better observational constraints on these quantities will lead to significant improvements in the precision of projections of future Arctic climate change.
\end{abstract}

Keywords Arctic $\cdot$ Sea ice $\cdot$ Climate change

D. L. R. Hodson $(\square)$ · S. P. E. Keeley · E. Hawkins

NCAS-Climate, Department of Meteorology,

University of Reading, Earley Gate,

PO Box 243, Reading RG6 6BB, UK

e-mail: d.1.r.hodson@ reading.ac.uk

A. West · J. Ridley $\cdot$ H. T. Hewitt

Met Office, FitzRoy Road, Exeter, Devon EX1 3PB, UK

\section{Introduction}

The Arctic region is expected to undergo rapid climatic changes in the 21 st century in response to anthropogenic warming, for example rising temperatures (Chapman and Walsh 2007), reduced sea ice (Zhang and Walsh 2006) and snow cover (Symon et al. 2005), melting permafrost (Lawrence et al. 2008), increased precipitation (Kattsov et al. 2007), reduced stability in the wintertime Arctic atmosphere (Pavelsky et al. 2010) and increased cloud cover (Vavrus et al. 2009).

However, these studies also demonstrate that there is a wide variation in the size of these projected changes between climate models. In order to begin to improve and constrain future Arctic projections, the uncertainties associated with these projections need to be quantified, understood and potentially attributed to a particular source.

Uncertainties have been examined in detail for the future Arctic climate projections within the CMIP3 global climate model ensemble (Solomon et al. 2007) by a range of previous studies. Liu et al. (2008), for example, examined the variation in Arctic surface air temperature across the CMIP3 ensemble, Kattsov et al. (2007) -Arctic precipitation, Holland et al. (2010)—-the Sea Ice mass budget and Eisenman et al. (2007)—Arctic cloud cover and Longwave radiation fluxes. However, all these studies use a diverse set of approaches and definitions to examine a particular aspect of Arctic climate projections. It is therefore difficult to draw clear comparisons between them in order to quantify and understand uncertainty in processes across the Arctic region. The goal of this paper, therefore, is to consistently and systematically assess and quantify the uncertainties in projections of Arctic climate change, across a range of local processes, and to attempt to discover and attribute the sources of these uncertainties. To put this 
analysis in contact, we first briefly discuss the factors affecting Arctic Climate and the sources of uncertainty in model projections of Arctic Climate.

\subsection{Arctic climate}

The mean climate of the Arctic arises as a balance between a range of Arctic processes (Fig. 1). The temperature and salinity profiles in the ocean and the temperature and humidity profiles in the atmosphere play a key role. The structures of these profiles are highly seasonal, and changes in the annual mean are likely to arise from a change in the balance of the seasonally varying forcings. For example, the atmospheric temperature inversion arises as a consequence of surface radiative cooling together with a number of other factors [warm air advection, subsidence, cloud processes, surface melt, topography—see Curry et al. (1996)]. In the ocean, temperature and salinity profiles arise from freshwater runoff from the land surface, sea ice melting and ocean advection. The resultant cold, low salinity waters can insulate the overlying sea ice from deeper, warmer waters (Bourgain et al. 2011).

There are strong feedbacks within the system. As the ocean sea ice (high albedo) melts it reveals a darker (low albedo) ocean surface-resulting in increased absorption of solar (shortwave) radiation, causing an additional warming and increased melting [ice-albedo feedback-Winton (2006)]. As overlying sea ice insulates the atmosphere from the ocean surface, increased melting leads to increase heat and moisture fluxes into the atmosphere. These increased fluxes may in turn lead to increases in high altitude cloud

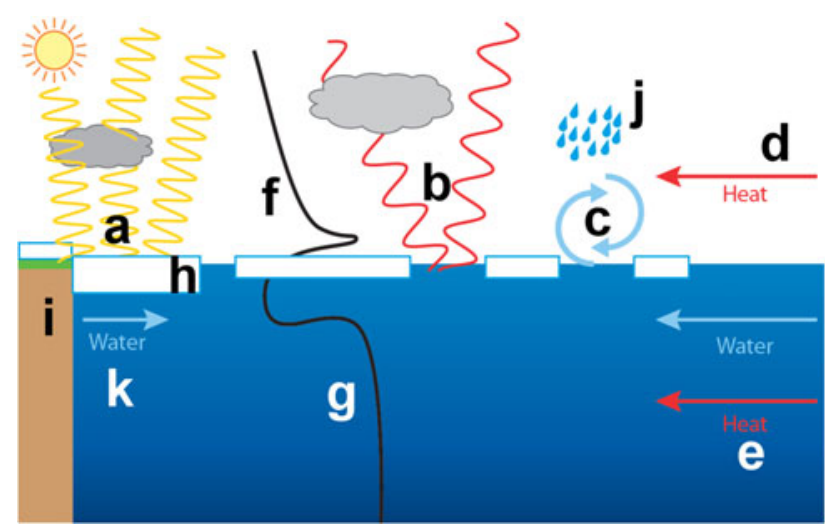

Fig. 1 Key processes governing Arctic climate. a Net shortwave (SW) solar radiation (modulated by scattering of radiation by clouds and surface albedo). $b$ Net longwave radiation emitted by surface and by clouds. $c$ Turbulent (sensible + latent) fluxes. $d$ Atmosphere heat transport. $e$ Ocean heat transport. $f$ Atmosphere temperature profile. $g$ Ocean temperature/salinity profile. $h$ Sea ice, thickness and extent. $i$ Land surface processes. $j$ Precipitation. $k$ Freshwater flux e.g. from rivers. Sarah Keeley/Rob Hine ECMWF cover, resulting in reduced outgoing longwave radiation losses from the surface-leading to surface that is warmer than otherwise [cloud-radiation feedback-Abbot et al. (2009)]. The increased high altitude clouds are accompanied by increased specific humidity, which traps more of the outgoing surface longwave radiation-also leading to increased surface warming [water-vapour feedback-Curry et al. (1995)].

The global response to increased atmospheric $\mathrm{CO}_{2}$ concentration can alter the northward heat transport into the Arctic, resulting in changing forcings from ocean and the atmosphere. A reduction in sea ice cover can also directly feedback on the heat transports by reducing the meridional global temperature gradient. Land processes also play a key role in Arctic climate-a retreat of the seasonal snow cover reduces the land surface albedo leading to anomalous warming, and melting of permafrost increases the availability of soil moisture for evaporation. These can result in changes to the Arctic freshwater budget, via precipitation and river runoff changes, which can ultimately alter the ocean surface salinity, and hence stability.

Some processes that occur within the climate system are not represented within the CMIP3 climate models [see Randall et al. (2007)]. For example land-fast ice and biological processes of the shelf seas of the Arctic are still not resolved in models. Land surface schemes, due to a lack of vertical depth in the soil, are not able to represent permafrost well. A number of processes are under development for inclusion in future Earth System models that may be important for Arctic Climate, e.g. interactive chemistry and biogeochemistry. Such missing processes represent an uncertainty in the modelling of Arctic climate-one we are currently unable to quantify or assess. The CMIP5 and future ensembles are likely to include improvements in these areas.

\subsection{Sources of uncertainty}

There are four sources of uncertainty in climate model projections of Arctic climate:

- Scenario uncertainty-Uncertainty in future levels of greenhouse gases.

- Structural uncertainty-The different methods different models use to represent the same physical process e.g. Model resolution, coordinate systems (e.g. constant density vs. constant height).

- Parameter uncertainty-The value of a parameter within a parameterization of a process not explicitly physically resolved in a climate model (e.g. surface ice albedo) chosen from within the given observational range. 
- Intrinsic internal variability-The inherent variability, or noise, within the climate system, due to its chaotic nature.

The relative impact of these sources of uncertainty on Arctic climate over time can be seen in Fig. 2, following the methods of Hawkins and Sutton (2009, 2011) Model uncertainty (structural plus parameter uncertainty) dominates these quantities in the near term, but scenario uncertainty dominates in the long term.

We do not consider scenario uncertainty in this paper, since this is defined by external factors such as population growth, technology and economics. We therefore eliminate this source of uncertainty by examining the behaviour of the Arctic climate when subjected to a concentration of

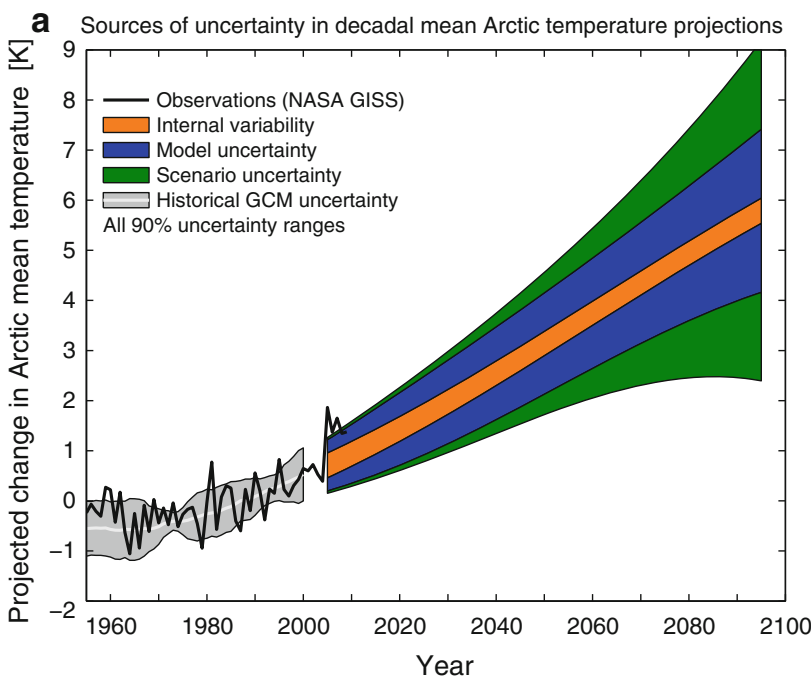

b Sources of uncertainty in decadal mean Arctic precipitation projections

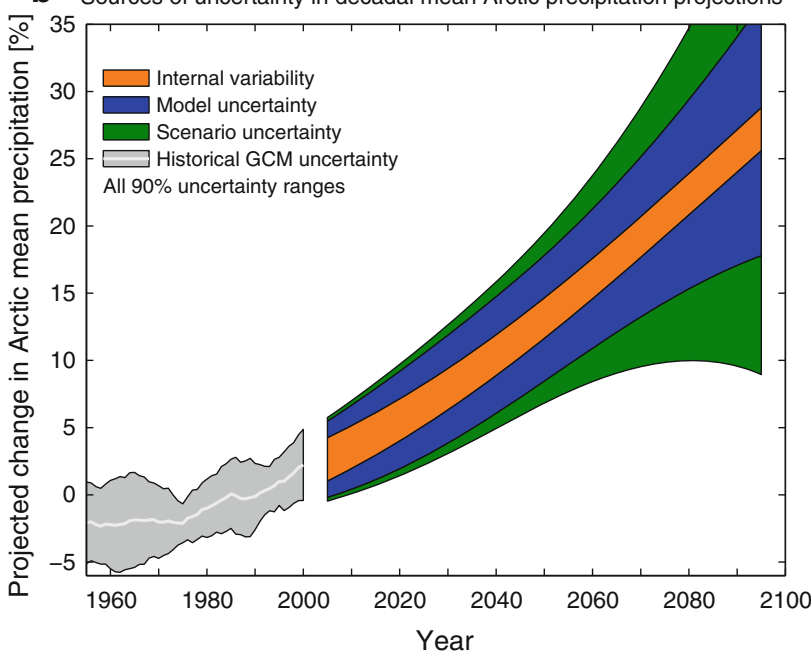

Fig. 2 The total uncertainty in projected Arctic temperature (a) and precipitation (b) is separated into its various components using the CMIP3 ensemble projections of Arctic climate, using the methods of Hawkins and Sutton $(2009,2011)$. The black line represents the observations for temperature from the NASA GISS dataset Hansen et al. (2010)
$\mathrm{CO}_{2}$ double that of pre-industrial levels. This is reasonable, since any improvements that bring about a reduction in projection uncertainty are likely to come through the modifications to model structures and parameters rather than increased certainty about future greenhouse gas emissions. Any reduction in uncertainty is ultimately limited by the intrinsic model internal variability.

\subsection{Model parameterization}

Many important climate processes are not modelled explicitly in current climate models. Such processes occur on a spatial scale (e.g. convection) or timescale (e.g. cloud microphysics) that is below the resolution of the model, and so are represented in a simplified way-often as a statistical or generalised representation of a process for an entire model grid box. Such simplified models are termed parameterizations. For example, the surface albedo within the Arctic can vary dramatically within an area of the size of model grid box. Even if an entire grid box was full of sea ice there would be variations in albedo due to pooling of water on the ice, snow depth and leads etc. Therefore over the tens of kilometres represented in one model grid box a simplified or parameterized version of the actual physical processes is applied. Such parameterizations may be weakly constrained by observations and as such may potentially be a means to tune models to the mean observed climate.

As noted above, the two goals of this study are to:

- systematically assess the uncertainty in simulations of current and future Arctic climate.

- assess and understand the causes of the uncertainty in future projections of Arctic climate.

The structure of this paper is as follows. Section 2 describes the models, experiments and methods used in this study. Section 3 describes the results of the analysis of model uncertainty. Section 4 discusses the implications of the results and summarises our conclusions. (This study is a synthesis and summary of a systematic review of Arctic Uncertainty conducted for the UK National Environmental Research Council (Hodson et al. 2010).)

\section{Models and methods}

There are a variety of definitions of the Arctic region in use across the literature. Because relevant Arctic land processes (e.g. permafrost) are poorly represented in current models, we choose to define the Arctic as the region north of $70^{\circ} \mathrm{N}$. This incorporates more ocean grid points $(70 \%)$ than land grid points $(30 \%)$ and hence will weight the assessment to consider the importance of ocean and sea ice 

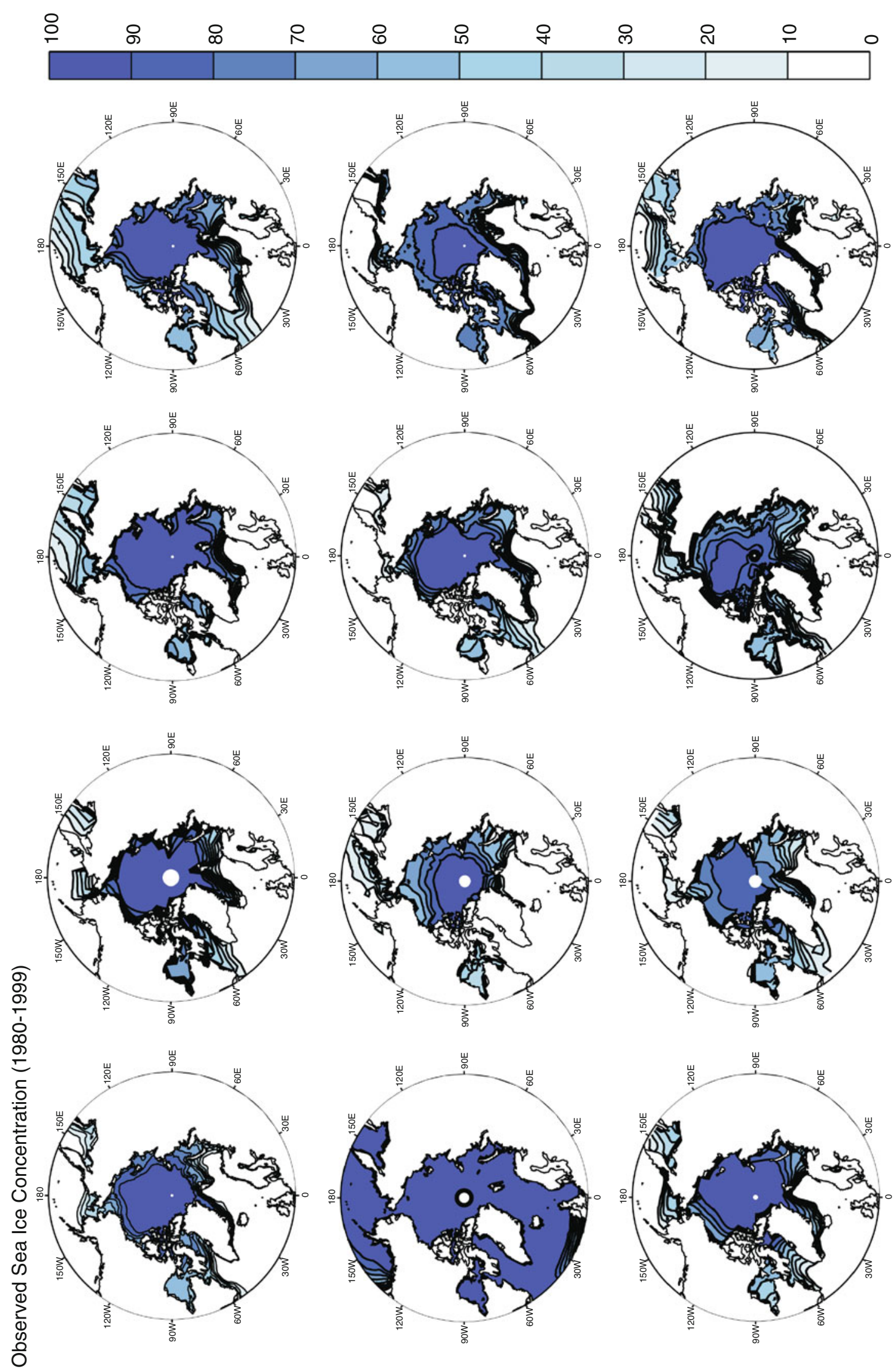
4 Fig. 3 Climatology of sea ice fraction in the Control experiment for 11 of the CMIP3 models (including IAP-FGOALS) compared with the Observed Sea ice fraction (1980-1999) (upper left)

processes over land processes. All area average quantities are therefore calculated between $70^{\circ} \mathrm{N}$ and $90^{\circ} \mathrm{N}$. To simplify the analysis we will examine only annual mean Arctic variables in this study. In order to compare the different sources of model uncertainty discussed above, we examined two ensembles: a multi-model ensemble (CMIP3), and a perturbed-parameter ensemble of the Hadley Centre model HadCM3, to be referred to as the THC-QUMP ensemble.

\subsection{CMIP3}

The CMIP3 multi model ensemble contains 22 coupled climate models [see Table 1, Randall et al. (2007)]. The models vary in their structure, parameterization, resolution, and whether or not they employ flux adjustments to ensure a stable climate. The variance in model structure arises from the different approximations and numerical methods used to model the equations that describe physical process (e.g. fluid flow, radiation) and also the interaction with the different co-ordinate systems that may be employed (e.g. vertical levels vs. density levels, location of poles (over land or ocean) etc). Models also differ in the way in which they represent sub-gridscale processes (parameterization). The inter-model variations in these methods contribute to the structural and parameter uncertainty in climate projections.

\subsection{THC-QUMP}

The 22 member THC-QUMP ensemble was created by perturbing parameters within model parameterizations (e.g. cloud formation and precipitation and ice structure and

Table 1 Models comprising the CMIP3 ensemble used in this study

\begin{tabular}{lll}
\hline bccr bcm2.0 & cccma cgcm 3.1 t47 & cnrm cm3 \\
csiro mk3.0 & csiro mk3.5 & gfdl cm2.0 \\
gfdl cm2.1 & giss model eh & giss model e r \\
ingv echam4 & inmcm3.0 & ipsl cm4 \\
miroc3.2 hires & miroc3.2 medres & miub echo g \\
mpi echam5 & mri cgcm2.3.2a & ncar ccsm 3.0 \\
ncar pcm1 & ukmo hadgem1 & ukmo hadcm3
\end{tabular}

Not all variables are stored for all models. Hence for many parts of the analysis in this study only a subset of this model set was used. Significance testing, where applied, has been adjusted to reflect this. Pre-industrial controls (picntrl) were available for all models except those in bold-where present-day controls (pdentrl) were used instead albedo) to within likely ranges. The ensemble can be broadly described as atmospheric parameter changes without flux correction. The aim of the ensemble is to span the range of climate sensitivities consistent with a uniform prior on parameters but in the process maximise the chance of getting plausible model versions and span a wide range of parameter settings-in other words an attempt is made to uniformly sample the parameter space consistent with a stable climate-for more details see: Murphy et al. (2004), Stainforth et al. (2005), and Collins et al. (2006, 2011). The ensemble comprises of the unperturbed member, the base state which has the same parameter settings as HadCM3 in the CMIP3 ensemble, and other members that have been perturbed away from the base state through changes to multiple model parameters. The perturbations were chosen according to a "Latin Hypercube" design which maximises the number of potential interactions between perturbations. The parameter perturbations are shown in detail in Tables 2, 3, 4, 5, and 6 .

The perturbations were chosen to span the range of observational uncertainty at the time of the experiment design, with the aim of producing a series of experiments with a wide range of climate sensitivities. (Note that this meant that the albedo of cold ice was not perturbed at all). In additional, several parametization schemes were switched on or off.

Some parameters were perturbed as a linked set, namely threshold for cloud to rain conversion rate, cloud fraction at saturation, sea ice albedo, surface gravity wave parameters, forest roughness lengths, number of soil levels accessed for evapotranspiration. Perturbations requiring a logical switch involved invoking an additional feature or process (nonspherical ice particles, shortwave water vapour continuum absorption, sulphur cycle, surface-canopy energy exchange), removing a process (dependence of stomatal conductance on $\mathrm{CO}_{2}$ ) or altering the method of representing a process (flow dependent Rhcrit, vertical gradient of cloud water in grid box).

Perturbations to these parameters causes some minor climate drift in some ensemble members. However, no flux adjustment was applied to nudge these members back to the climatology of the unperturbed model (Vellinga and $\mathrm{Wu}$ 2008). Some ensemble members exhibit climate drift in the Arctic resulting in low initial states of sea ice extent, such that the summer ice cover was lost early on in the $2 \times$ $\mathrm{CO}^{2}$ experiments.

Each member was first integrated for 100 years as a spin-up, to assess the amount of climate drift and model stability. Model experiments were then initialized from the end of these spin-up integrations. Across the ensemble a gradual weakening of the Meridional Overturning Circulation (MOC) occurs as $\mathrm{CO}_{2}$ concentrations increase, within the range reported in the Third Assessment Report 
Table 2 Perturbed parameter values for the THC-QUMP ensemble

\begin{tabular}{|c|c|c|c|c|c|c|c|c|}
\hline & VF1 & $\mathrm{CT}$ & CWland & Cwsea & RHCrit & eacfbl & eacftrp & rhcrit2 \\
\hline 1 & 1.32222 & $6.30 \mathrm{E}-05$ & $2.28 \mathrm{E}-04$ & $5.70 \mathrm{E}-05$ & 0.6692 & 0.5106 & 0.5053 & 0 \\
\hline 2 & 0.93337 & $5.10 \mathrm{E}-05$ & $1.26 \mathrm{E}-04$ & $2.78 \mathrm{E}-05$ & 0.7151 & 0.5157 & 0.50786 & 0 \\
\hline 3 & 0.78497 & $8.80 \mathrm{E}-05$ & $1.50 \mathrm{E}-04$ & $3.50 \mathrm{E}-05$ & 0.69537 & 0.5417 & 0.52086 & 0 \\
\hline 4 & 0.70951 & $1.69 \mathrm{E}-04$ & $1.66 \mathrm{E}-03$ & $4.15 \mathrm{E}-04$ & 0.68539 & 0.5284 & 0.51419 & 0 \\
\hline 5 & 0.99786 & $9.70 \mathrm{E}-05$ & $1.33 \mathrm{E}-04$ & $2.99 \mathrm{E}-05$ & 0.80257 & 0.5748 & 0.53741 & 0 \\
\hline 6 & 1.07324 & $3.17 \mathrm{E}-04$ & $1.91 \mathrm{E}-04$ & $4.73 \mathrm{E}-05$ & 0.7 & 0.6855 & 0.59273 & 1 \\
\hline 7 & 0.81076 & $1.27 \mathrm{E}-04$ & $1.42 \mathrm{E}-04$ & $3.26 \mathrm{E}-05$ & 0.63896 & 0.5008 & 0.5004 & 0 \\
\hline 8 & 1.32823 & $2.22 \mathrm{E}-04$ & $1.55 \mathrm{E}-04$ & $3.65 \mathrm{E}-05$ & 0.68506 & 0.7189 & 0.60947 & 0 \\
\hline 9 & 1.12592 & $9.10 \mathrm{E}-05$ & $5.21 \mathrm{E}-04$ & $1.30 \mathrm{E}-04$ & 0.7 & 0.5232 & 0.51158 & 1 \\
\hline 10 & 0.8223 & $7.20 \mathrm{E}-05$ & $1.41 \mathrm{E}-04$ & $3.23 \mathrm{E}-05$ & 0.85307 & 0.5458 & 0.5229 & 0 \\
\hline 11 & 0.99135 & $2.82 \mathrm{E}-04$ & $1.59 \mathrm{E}-03$ & $3.97 \mathrm{E}-04$ & 0.8045 & 0.7499 & 0.62494 & 0 \\
\hline 12 & 1.16724 & $2.34 \mathrm{E}-04$ & $1.51 \mathrm{E}-04$ & $3.53 \mathrm{E}-05$ & 0.7 & 0.5396 & 0.51982 & 1 \\
\hline 13 & 0.65009 & $6.60 \mathrm{E}-05$ & $9.98 \mathrm{E}-04$ & $2.50 \mathrm{E}-04$ & 0.65163 & 0.5084 & 0.5042 & 0 \\
\hline 14 & 1.42575 & $3.80 \mathrm{E}-04$ & $6.78 \mathrm{E}-04$ & $1.69 \mathrm{E}-04$ & 0.7 & 0.5923 & 0.54616 & 1 \\
\hline 15 & 0.86979 & $2.62 \mathrm{E}-04$ & $1.41 \mathrm{E}-04$ & $3.23 \mathrm{E}-05$ & 0.68998 & 0.7889 & 0.64447 & 0 \\
\hline 16 & 0.97361 & $2.40 \mathrm{E}-04$ & $1.69 \mathrm{E}-03$ & $4.22 \mathrm{E}-04$ & 0.83177 & 0.7992 & 0.64961 & 0 \\
\hline 17 & 1.15748 & $3.15 \mathrm{E}-04$ & $1.86 \mathrm{E}-04$ & $4.58 \mathrm{E}-05$ & 0.68549 & 0.7893 & 0.64466 & 0 \\
\hline 18 & 0.84221 & $2.28 \mathrm{E}-04$ & $4.13 \mathrm{E}-04$ & $1.03 \mathrm{E}-04$ & 0.7 & 0.5322 & 0.51608 & 1 \\
\hline 19 & 1.54799 & $1.44 \mathrm{E}-04$ & $4.27 \mathrm{E}-04$ & $1.07 \mathrm{E}-04$ & 0.88424 & 0.6227 & 0.56133 & 0 \\
\hline 20 & 2 & $5.00 \mathrm{E}-05$ & $2.00 \mathrm{E}-03$ & $5.00 \mathrm{E}-04$ & 0.9 & 0.5 & 0.5 & 0 \\
\hline 21 & 1 & $5.00 \mathrm{E}-05$ & $1.00 \mathrm{E}-04$ & $2.00 \mathrm{E}-05$ & 0.9 & 0.7 & 0.6 & 0 \\
\hline 22 & 1 & $1.00 \mathrm{E}-04$ & $2.00 \mathrm{E}-04$ & $5.00 \mathrm{E}-05$ & 0.7 & 0.5 & 0.5 & 0 \\
\hline
\end{tabular}

Ensemble member 22 is the standard HadCM3 configuration - and has the sulphur cycle turned off. All other members have the sulphur cycle turned on. Descriptions of the parameters are given in Table 6

(Cubasch et al. 2001). No rapid shutdown of the MOC is seen.

Both ensembles allow sampling of parameter uncertainty and internal variability in future projections. The CMIP3 ensemble allows the sampling of both parameter and structural uncertainty (see Sect. 2.1). It is clear that parameter uncertainty and structural uncertainty are not independent quantities, since climate models are in part constrained by past observations of climate. Hence it is likely that some of the structural uncertainty is compensated by the parameter uncertainty, i.e. parameters are tuned within uncertainty to compensate for biases introduced by structural uncertainties-and hence are likely to be negatively correlated with each other. This means that we cannot deduce whether parameter or structural uncertainty plays a greater role in a given process from a simple comparison of the CMIP3 and THC-QUMP ensembles.

\subsection{Model experiments}

For each model in the ensemble, two experiments were performed: a Control integration and a $2 \times \mathrm{CO}_{2}$ experiment. In the Control integration the atmospheric concentration of carbon dioxide $\left(\mathrm{CO}_{2}\right)$ is held at a constant level throughout the model experiment (usually pre-industrial levels of 290 ppmv-although three models used present day levels 348 ppmv-see Table 1); any variations in the climate system seen in this experiment are hence solely due to internal variability. In the $2 \times \mathrm{CO}_{2}$ experiment the carbon dioxide concentration is increased at a rate of $1 \%$ per year starting from the $\mathrm{CO}_{2}$ concentration in the control integration. Hence at around year 70 of the $2 \times \mathrm{CO}_{2}$ experiment, the $\mathrm{CO}_{2}$ concentration is double that of the control integration.

\subsection{Estimation of internal variability}

The spread in climate variables across models (e.g. Fig. 3) may occur due to differences in parameterization and model structure, as discussed above. But it may also arise as a consequence of sampling the underlying internal climate variability. A rigorous treatment of the internal variability would involve a full Analysis of Variance (ANOVA) (see von Storch and Zwiers 2002; Yip et al. 2011; Hodson and Sutton 2008), but here we simply calculate an estimate of the internal variability contribution to the overall model spread. For a given variable $X_{m}$, where $m$ is the ensemble member and $t$ is time, we assume a normal 
Table 3 Perturbed parameter values for the THC-QUMP ensemble

\begin{tabular}{|c|c|c|c|c|c|c|c|c|c|c|}
\hline & Ent & ice1 & cape & conv & anvil & MinSIA & MaxSIA & ice 2 & ice1 & ice 0 \\
\hline 1 & 2.98472 & 9.5171 & -999 & 0.3036 & 2.61912 & 0.5068 & 0.8 & 3 & 9.5171 & 2 \\
\hline 2 & 2.89538 & 3.827 & 1.23 & -999 & -999 & 0.6013 & 0.8 & 3 & 3.827 & 2 \\
\hline 3 & 2.822 & 8.5807 & -999 & -999 & -999 & 0.5199 & 0.8 & 7 & 8.5807 & 7 \\
\hline 4 & 3.12813 & 9.9264 & 1.7 & 0.60104 & 1.03742 & 0.501 & 0.8 & 3 & 9.9264 & 2 \\
\hline 5 & 2.90642 & 9.325 & 3.03 & -999 & -999 & 0.5095 & 0.8 & 3 & 9.325 & 2 \\
\hline 6 & 4.3085 & 7.9421 & 2.67 & -999 & -999 & 0.5288 & 0.8 & 3 & 7.9421 & 2 \\
\hline 7 & 3.71544 & 7.9179 & -999 & -999 & -999 & 0.5292 & 0.8 & 3 & 7.9179 & 2 \\
\hline 8 & 2.76858 & 6.2121 & 1.89 & -999 & -999 & 0.553 & 0.8 & 3 & 6.2121 & 2 \\
\hline 9 & 2.97842 & 9.3729 & -999 & -999 & -999 & 0.5088 & 0.8 & 7 & 9.3729 & 7 \\
\hline 10 & 4.08631 & 9.7071 & 3.42 & -999 & -999 & 0.5041 & 0.8 & 3 & 9.7071 & 2 \\
\hline 11 & 3.03335 & 9.2929 & 1.58 & 0.46707 & 2.06581 & 0.5099 & 0.8 & 3 & 9.2929 & 2 \\
\hline 12 & 4.96524 & 9.7279 & 2.76 & -999 & -999 & 0.5038 & 0.8 & 3 & 9.7279 & 2 \\
\hline 13 & 2.61114 & 4.6212 & -999 & 0.92649 & 1.60046 & 0.5801 & 0.8 & 3 & 4.6212 & 2 \\
\hline 14 & 4.85597 & 8.4886 & -999 & 0.14225 & 2.51386 & 0.5212 & 0.8 & 3 & 8.4886 & 2 \\
\hline 15 & 3.12616 & 3.1456 & -999 & 0.49732 & 1.80094 & 0.6195 & 0.8 & 3 & 3.1456 & 2 \\
\hline 16 & 3.08109 & 4.6531 & 1.05 & 0.33453 & 1.32774 & 0.5793 & 0.8 & 3 & 4.6531 & 2 \\
\hline 17 & 2.44041 & 8.9729 & -999 & 0.95753 & 1.16415 & 0.5144 & 0.8 & 7 & 8.9729 & 7 \\
\hline 18 & 5.10407 & 9.3464 & 1.96 & -999 & -999 & 0.5092 & 0.8 & 3 & 9.3464 & 2 \\
\hline 19 & 4.85869 & 9.2357 & 2.22 & -999 & -999 & 0.5107 & 0.8 & 3 & 9.2357 & 2 \\
\hline 20 & 3 & 10 & -999 & -999 & -999 & 0.5 & 0.8 & 3 & 10.0 & 2 \\
\hline 21 & 3 & 10 & -999 & -999 & -999 & 0.5 & 0.8 & 3 & 10.0 & 2 \\
\hline 22 & 3 & 10 & -999 & -999 & -999 & 0.5 & 0.8 & 3 & 10.0 & 2 \\
\hline
\end{tabular}

Ensemble member 22 is the standard HadCM3 configuration - and has the sulphur cycle turned off. All other members have the sulphur cycle turned on. Descriptions of the parameters are given in Table 6

distribution with a mean $\mu_{m}$ and variance $\sigma_{\text {int }}^{2}: X_{m t} \sim$ $N\left(\mu_{m}, \sigma_{\text {int }}^{2}\right)$. An estimate of internal variability $\hat{\sigma}_{\text {int }}$ is given by:

$\hat{\sigma}_{\text {int }}=\left(\frac{1}{M} \sum_{m=1}^{M} \frac{1}{T-1} \sum_{t=1}^{T}\left(X_{m t}-\bar{X}_{m}\right)^{2}\right)^{1 / 2}$

for $M$ ensemble members and $T$ time points. Here $\bar{X}_{m}$ is the time mean:

$\bar{X}_{m}=\frac{1}{T} \sum_{t=1}^{T} X_{m t}$

i.e. (1) is the square root of the mean of the time variance in the Control integrations, across the ensemble. In this case we used 80 years of the control run $(\mathrm{T}=80)$. Given this estimate of internal variability, for an ensemble composed of 20 years means (sampled from the control integration), we would expect a spread in the means due to sampling of internal variability $\left(\sigma_{v}\right)$ of:

$\sigma_{v}=\frac{\hat{\sigma}_{i n t}}{\sqrt{20}}$
This is the spread we would expect between the 20 year means of each control integration if the true long-term means were identical. Hence it is the minimum contribution we expect from internal variability alone. If we assume that the magnitude of the internal variability is the same in the $2 \times \mathrm{CO}_{2}$ experiment as the Control integration, then minimum spread we expect between the mean projected changes $\left(2 \times \mathrm{CO}_{2}\right.$-Control $)$ across an ensemble will be: $\hat{\sigma}_{\text {int }} \sqrt{2} / \sqrt{20}$ - since the variances sum.

Does this measure capture the full effect of internal variability? Each model in the ensemble is initialised from different initial conditions. Since we remove the 80 year mean in computing (1) we may remove the impact of initial conditions. For example, each model may be in different phases of a longer multi-decadal oscillation, or minor differences in atmospheric initial conditions may trigger such oscillations. Perturbed initial condition ensembles would be required to refine this measure of internal variability further, for example Mahlstein and Knutti (2012) and Deser et al. (2012). For this reason we can only consider (3) to be a lower bound estimate for the contribution from internal variability. 
Table 4 Perturbed parameter values for the THC-QUMP ensemble

\begin{tabular}{|c|c|c|c|c|c|c|c|c|c|c|}
\hline & ice 3 & ice 4 & k-gwd & $\operatorname{diff} 2$ & length1 & $\mathrm{H} 2 \mathrm{O}$ & diff1 & gwd & ice 5 & ice6 \\
\hline 1 & $3.33 \mathrm{E}-04$ & 29.804 & $1.04 \mathrm{E}+04$ & 22.047 & 0.08307 & 0 & 6 & 3 & 1 & 1 \\
\hline 2 & $3.62 \mathrm{E}-04$ & 30.653 & $1.74 \mathrm{E}+04$ & 20.529 & 0.22654 & 1 & 6 & 5 & 1 & 1 \\
\hline 3 & $3.71 \mathrm{E}-04$ & 39.82 & $1.15 \mathrm{E}+04$ & 18.797 & 0.16492 & 1 & 6 & 3 & 7 & 7 \\
\hline 4 & $3.72 \mathrm{E}-04$ & 34.19 & $1.28 \mathrm{E}+04$ & 8.785 & 0.49288 & 0 & 6 & 5 & 1 & 1 \\
\hline 5 & $3.42 \mathrm{E}-04$ & 25.596 & $1.92 \mathrm{E}+04$ & 15.208 & 0.32231 & 0 & 6 & 3 & 1 & 1 \\
\hline 6 & $3.49 \mathrm{E}-04$ & 35.638 & $1.03 \mathrm{E}+04$ & 17.092 & 0.05844 & 1 & 6 & 3 & 1 & 1 \\
\hline 7 & $3.49 \mathrm{E}-04$ & 29.8 & $1.15 \mathrm{E}+04$ & 10.662 & 0.10553 & 1 & 6 & 5 & 1 & 1 \\
\hline 8 & $3.67 \mathrm{E}-04$ & 28.263 & $1.81 \mathrm{E}+04$ & 7.079 & 0.07065 & 1 & 4 & 3 & 1 & 1 \\
\hline 9 & $3.68 \mathrm{E}-04$ & 33.789 & $1.75 \mathrm{E}+04$ & 10.784 & 0.13415 & 0 & 6 & 5 & 7 & 7 \\
\hline 10 & $3.34 \mathrm{E}-04$ & 28.509 & $1.04 \mathrm{E}+04$ & 11.122 & 0.11022 & 0 & 6 & 3 & 1 & 1 \\
\hline 11 & $3.55 \mathrm{E}-04$ & 28.756 & $1.95 \mathrm{E}+04$ & 15.659 & 0.12417 & 0 & 4 & 5 & 1 & 1 \\
\hline 12 & $3.52 \mathrm{E}-04$ & 38.412 & $1.97 \mathrm{E}+04$ & 14.006 & 0.224 & 0 & 6 & 3 & 1 & 1 \\
\hline 13 & $3.73 \mathrm{E}-04$ & 36.419 & $1.57 \mathrm{E}+04$ & 13.212 & 0.10996 & 1 & 6 & 3 & 1 & 1 \\
\hline 14 & $3.44 \mathrm{E}-04$ & 28.07 & $1.65 \mathrm{E}+04$ & 11.075 & 0.15263 & 0 & 6 & 3 & 1 & 1 \\
\hline 15 & $3.67 \mathrm{E}-04$ & 33.304 & $1.26 \mathrm{E}+04$ & 16.649 & 0.13947 & 0 & 6 & 5 & 1 & 1 \\
\hline 16 & $3.48 \mathrm{E}-04$ & 36.72 & $1.51 \mathrm{E}+04$ & 16.285 & 0.13698 & 0 & 6 & 5 & 1 & 1 \\
\hline 17 & $3.60 \mathrm{E}-04$ & 27.448 & $1.99 \mathrm{E}+04$ & 12.99 & 0.46636 & 0 & 6 & 5 & 7 & 7 \\
\hline 18 & $3.53 \mathrm{E}-04$ & 39.111 & $1.27 \mathrm{E}+04$ & 15.839 & 0.14292 & 0 & 6 & 5 & 1 & 1 \\
\hline 19 & $3.64 \mathrm{E}-04$ & 36.597 & $1.95 \mathrm{E}+04$ & 11.501 & 0.16253 & 1 & 4 & 3 & 1 & 1 \\
\hline 20 & $3.75 \mathrm{E}-04$ & 30 & $2.00 \mathrm{E}+04$ & 12 & 0.15 & 0 & 6 & 3 & 1 & 1 \\
\hline 21 & $3.75 \mathrm{E}-04$ & 30 & $2.00 \mathrm{E}+04$ & 12 & 0.15 & 0 & 6 & 3 & 1 & 1 \\
\hline 22 & $3.75 \mathrm{E}-04$ & 30 & $2.00 \mathrm{E}+04$ & 12 & 0.15 & 0 & 6 & 3 & 1 & 1 \\
\hline
\end{tabular}

Ensemble member 22 is the standard HadCM3 configuration-and has the sulphur cycle turned off. All other members have the sulphur cycle turned on. Descriptions of the parameters are given in Table 6

\section{Results}

We now analyse the CMIP3 and THC-QUMP ensembles to assess the magnitude of the uncertainty (spread) in both the model control climatology and the climate change $(2 \times$ $\mathrm{CO}_{2}$-Control) response (the spread in the difference between $2 \times \mathrm{CO}_{2}$ and Control integrations) in a number of key Arctic variables.

\subsection{Climatology and ensemble spread in key Arctic variables}

In this study we are principally concerned with the spread in the projected changes in the Arctic under a doubling in the concentration of atmospheric $\mathrm{CO}_{2}$. However, there is also a spread in the climatologies of the control integrations of the models, from which the changes are measured. This spread in climatologies would be unimportant if each model responded linearly to a doubling of $\mathrm{CO}_{2}$. However, as will be shown, the initial model state (or climatology) can determine the magnitude of the projected changes. Hence we briefly outline the spread in the climatologies. As noted above, we only consider annual mean quantities here. The main differences in the CMIP3 model climatologies are well documented in the IPCC report (Randall et al. 2007). In Fig. 3 we present a 20 year mean sea ice fraction from the control integration of 11 of the CMIP3 models, together with the mean observed sea ice fractions (1980-1999). The Figure shows that there are a wide range of sea ice extents within the CMIP3 ensemble, with one model (IAP-FGOALS) having annual mean sea ice as far south as the UK. (For this reason, we exclude the IAPFGOALS model from the remainder of our analysis). This Figure also highlights the differences in spatial resolution across the ensemble and the subtleties of regional differences that may be hidden by analysis of the climatology within our chosen definition of the Arctic (e.g. $70^{\circ} \mathrm{N}$ ).

Table 7 shows estimates of the ensemble mean and ensemble spread for key Arctic variables in the control integrations of both the CMIP3 and THC-QUMP ensembles. The table also shows an estimate of the fraction of the ensemble spread that is simply due to sampling of the internal (or inter-annual) variability within each model. As noted above, this must be considered a lower bound, since we are unable to explicitly sample the uncertainty in initial conditions.

The mean sea ice extent and volume, surface air temperature and precipitation (Table 7) are consistent (within one standard deviation) between the THC-QUMP and CMIP3 ensembles. The mixed layer temperatures, however, are not 
Table 5 Perturbed parameter values for the THC-QUMP ensemble

\begin{tabular}{|c|c|c|c|c|c|c|c|c|}
\hline & k-lee-gwd & charnock & rough & boundary & canopy & forest1 & stomatal & forest 2 \\
\hline 1 & $1.56 \mathrm{E}+05$ & 0.0167 & $7.12 \mathrm{E}-04$ & 5.1062 & 1 & 0 & 0 & 2 \\
\hline 2 & $2.61 \mathrm{E}+05$ & 0.0126 & $1.85 \mathrm{E}-03$ & 7.7027 & 0 & 0 & 0 & 2 \\
\hline 3 & $1.72 \mathrm{E}+05$ & 0.0148 & $2.73 \mathrm{E}-04$ & 15.5736 & 0 & 0 & 0 & 2 \\
\hline 4 & $1.92 \mathrm{E}+05$ & 0.0161 & $1.31 \mathrm{E}-03$ & 6.7025 & 0 & 3 & 0 & 2 \\
\hline 5 & $2.88 \mathrm{E}+05$ & 0.0146 & $1.21 \mathrm{E}-03$ & 14.7922 & 1 & 3 & 1 & 4 \\
\hline 6 & $1.54 \mathrm{E}+05$ & 0.0138 & $2.81 \mathrm{Ev} 03$ & 8.8159 & 0 & 0 & 0 & 2 \\
\hline 7 & $1.72 \mathrm{E}+05$ & 0.0125 & $1.11 \mathrm{E}-03$ & 7.6657 & 0 & 2 & 0 & 4 \\
\hline 8 & $2.72 \mathrm{E}+05$ & 0.0151 & $4.68 \mathrm{E}-03$ & 7.5783 & 0 & 0 & 0 & 2 \\
\hline 9 & $2.62 \mathrm{E}+05$ & 0.0126 & $4.52 \mathrm{E}-03$ & 9.8408 & 1 & 3 & 0 & 4 \\
\hline 10 & $1.56 \mathrm{E}+05$ & 0.0184 & $3.84 \mathrm{E}-03$ & 14.6444 & 0 & 3 & 0 & 4 \\
\hline 11 & $2.92 \mathrm{E}+05$ & 0.0183 & $5.38 \mathrm{E}-04$ & 13.5766 & 0 & 0 & 0 & 4 \\
\hline 12 & $2.96 \mathrm{E}+05$ & 0.0144 & $4.62 \mathrm{E}-03$ & 6.6615 & 0 & 3 & 0 & 4 \\
\hline 13 & $2.36 \mathrm{E}+05$ & 0.0134 & 8.96Ev04 & 13.9517 & 0 & 3 & 1 & 2 \\
\hline 14 & $2.48 \mathrm{E}+05$ & 0.0155 & $3.54 \mathrm{E}-03$ & 15.5547 & 0 & 3 & 0 & 4 \\
\hline 15 & $1.89 \mathrm{E}+05$ & 0.019 & $4.56 \mathrm{E}-03$ & 12.9209 & 0 & 0 & 1 & 4 \\
\hline 16 & $2.26 \mathrm{E}+05$ & 0.0154 & $4.03 \mathrm{E}-03$ & 5.1791 & 0 & 0 & 0 & 2 \\
\hline 17 & $2.98 \mathrm{E}+05$ & 0.0138 & $3.35 \mathrm{E}-03$ & 7.8995 & 0 & 0 & 1 & 4 \\
\hline 18 & $1.90 \mathrm{E}+05$ & 0.014 & $3.70 \mathrm{E}-03$ & 19.7066 & 0 & 1 & 1 & 4 \\
\hline 19 & $2.92 \mathrm{E}+05$ & 0.0141 & $3.23 \mathrm{E}-03$ & 8.8681 & 0 & 3 & 1 & 2 \\
\hline 20 & $3.00 \mathrm{E}+05$ & 0.012 & $1.30 \mathrm{E}-03$ & 10 & 0 & 0 & 1 & 4 \\
\hline 21 & $3.00 \mathrm{E}+05$ & 0.012 & $1.30 \mathrm{E}-03$ & 10 & 0 & 0 & 1 & 4 \\
\hline 22 & $3.00 \mathrm{E}+05$ & 0.012 & $1.30 \mathrm{E}-03$ & 10 & 0 & 0 & 1 & 4 \\
\hline
\end{tabular}

Ensemble member 22 is the standard HadCM3 configuration-and has the sulphur cycle turned off. All other members have the sulphur cycle turned on. Descriptions of the parameters are given in Table 6

consistent between ensembles. These means are comparable to the observational estimates that exist, although the observations do not generally lie within one standard deviation of the ensemble means. This is partly due to the varying definitions of the Arctic region used across different observational studies. For instance, observed surface air temperature estimates (Liu et al. 2008) were computed over a wider Arctic region than our chosen region $\left(>70^{\circ} \mathrm{N}\right)$, hence resulting in a warmer mean surface temperature due to the inclusion of warmer lower-latitude regions.

Some quantities have a large ensemble spread (uncertainty, one standard deviation across the ensemble) compare to their mean, (e.g sea ice volume, ${ }^{1}$ and mixed layer temperatures). Whilst others, notably surface air temperature and precipitation, have a smaller ensemble spread. Hence some Arctic quantities are modelled more precisely ${ }^{2}$ than others. Some of this spread will be due to systematic

\footnotetext{
${ }^{1}$ Note that the small spread in sea ice extent is due to our definition of the Arctic-within the control integration most models have extents further south than $70^{\circ} \mathrm{N}$. This also explains why the internal variability appears to be the dominant source of uncertainty in this variable.

${ }^{2}$ Although a modelled quantity may be precise (small ensemble spread, small uncertainty) - it may not be accurate e.g. it may have a large mean bias compared to observations.
}

differences between models but a portion will be due to sampling of the intrinsic internal variability within each control. We have estimated this contribution for each model (Table 7). It is clear that, although this contribution is larger for some quantities than others, it is not the dominant source of spread in the ensemble (except perhaps for sea ice extent in the THC-QUMP ensemble (see foot note 1). In other words, the ensemble spread in these variables is mostly due to the parameter and structural uncertainties contained within the ensemble, and is likely not solely an artifact of the sampling of internal (interannual) variability (although see Sect. 2.4). Note also, that the spread in quantities within the THC-QUMP ensemble are always smaller in magnitude than those in the CMIP3 ensemble. This implies that the parameter uncertainty is not likely to entirely explain the spread in the CMIP3 ensemble, and that structural uncertainty must play a role. ${ }^{3}$

\footnotetext{
${ }^{3}$ It is clear that these two sources of uncertainty are not independent in the CMIP3 ensemble, since climate models are in part constrained by past observations of climate. Hence it is likely that some of the structural uncertainty is compensated for by the parameter uncertainty, i.e. they are negatively correlated. This means that we cannot simply compare the CMIP3 and THC-QUMP ensembles to deduce whether parameter or structural uncertainty play a greater role in a given process.
} 
Table 6 Description of parameters in Tables 2, 3, 4, and 5

\begin{tabular}{|c|c|}
\hline Short name & Description \\
\hline VF1 & Ice fall speed \\
\hline CT & Cloud droplet to rain conversion rate \\
\hline CWland & Cloud droplet to rain threshold: land \\
\hline Cwsea & Cloud droplet to rain threshold: sea \\
\hline RHCrit & Threshold of rel humidity for cloud formation \\
\hline rhcrit2 & Flow dependent RHcrit \\
\hline eacfbl & Cloud fraction at saturation-boundary layer \\
\hline eacftrp & Cloud fraction at saturation-troposphere \\
\hline Ent & Entrainment rate coeff \\
\hline cape & Time scale for destruction of CAPE \\
\hline conv & Convective anvils: updraught factor \\
\hline anvil & Convective anvils: shape factor \\
\hline MinSIA & Ice Albedo at $0{ }^{\circ} \mathrm{C}$ \\
\hline MaxSIA & Ice Albedo at Tcold \\
\hline ice1 & Tcold \\
\hline ice3 & Ocean-ice diffusion \\
\hline ice4 & Ice particle size \\
\hline $\mathrm{H} 2 \mathrm{O}$ & shortwave vapour continuum absorbtion \\
\hline diff1 & order of diffusion operator \\
\hline $\operatorname{diff} 2$ & Diffusion e-folding time \\
\hline gwd & Starting level for gravity wave drag \\
\hline k-gwd & Surface gravity wave param: wavelength \\
\hline k-lee-gwd & Surface gravity wave param: trapped lee wave const \\
\hline canopy & Surface-canopy energy exchange \\
\hline forest1 & Forest roughness length \\
\hline stomatal & dependence of stomatal conductance on $\mathrm{CO}_{2}$ \\
\hline forest2 & No. of soil levels for evap in forest \\
\hline charnock & Charnock constant \\
\hline rough & Free convective roughness length over sea \\
\hline boundary & boundary layer flux profile param \\
\hline length1 & Asymptotic neutral mixing length param \\
\hline ice0 & Ice cystal type in stratiform cloud (SW) \\
\hline ice2 & Ice cystal type in convective cloud (SW) \\
\hline ice 5 & Ice cystal type in stratiform cloud (LW) \\
\hline ice6 & Ice cystal type in convective cloud (LW) \\
\hline
\end{tabular}

\subsection{Ensemble mean and spread in projected changes} under $2 \times \mathrm{CO}^{2}$

The ensemble mean and spread $(1 \sigma)$ in the projected changes under $2 \times \mathrm{CO}_{2}$ in key Arctic variables are shown in Table 8. There is a considerable variation in the spread between variables. In both ensembles, the spread in sea ice volume changes is about half the size of the ensemble mean change. However, changes in surface air temperature are much better constrained, with uncertainties less than a third of the mean change in both ensembles.

For some variables (e.g. sea ice volume) the THCQUMP spread is comparable to that in the CMIP3 ensemble: 55 versus $49 \%$ (the sampling of internal/interannual variability only accounts for a small part of the spread in both cases). Hence the sampling of parameter uncertainty (THC-QUMP) results in a similar uncertainty range for projections of ice volume change as does the sampling of structural and parameter uncertainty (CMIP3). We cannot however, confidently conclude that parameter uncertainty is the dominant contributor to uncertainty in the CMIP3 projections, since, as noted previously ${ }^{2}$ the parameter and structural uncertainties in the CMIP3 ensemble are very likely to be anti-correlated. Nevertheless, we can conclude that future constraints on model parameter uncertainty are likely to lead to a reduction in the uncertainty of future projections of sea ice volume.

The situation is somewhat different for surface air temperature-the sampling of parameter uncertainty (THC-QUMP) results in a much smaller uncertainty range than the CMIP3 ensemble. This implies that the sampled range of parameter uncertainty may not be sufficient to explain the projected spread in surface air temperatures in the CMIP3 ensemble, and that structural uncertainties, such as the boundary layer and cloud schemes along with the treatment of surface fluxes, may play a significant role. The caveats are that THC-QUMP may not have sampled the full range of parameter uncertainty present in the CMIP3 ensemble, although significant efforts were made to do so (Collins et al. 2006), and that some of the CMIP3 models may use different parameterization schemes.

Regardless of these caveats, it is clear from the table that, in both ensembles, the uncertainty in the spread is greater than the estimate of the contribution from the internal variability (except for sea ice extent in THCQUMP-but $\sec ^{1}$ ), where it never contributes more than half of the spread (although see Sect. 2.4). This implies that there may be scope for reducing uncertainties in Arctic projections by improving model structure and parameterizations, since projections are likely not dominated by interannual internal climate variability.

\subsection{The impact of the model control climatology on projected changes}

The time-mean response of each climate model to constant atmospheric greenhouse gas concentrations (control integration) varies between models-resulting in a spread in model climatologies (e.g. Fig. 3). Each $\mathrm{CO}_{2}$ doubling experiment is initialized from a state in the control integration. The spread in the control climates across the ensemble would be unimportant if the Arctic climate within the model responded linearly to the doubling of $\mathrm{CO}_{2}$. However, previous studies (e.g. Holland et al. 2010) have demonstrated that such a spread in the climatologies 
Table 7 Mean and Spread of key Arctic variables in the control integrations (20 years)

\begin{tabular}{|c|c|c|c|c|c|}
\hline Ensemble & $\begin{array}{l}\text { Ice extent } / 10^{6} \\
\mathrm{~km}^{2}\end{array}$ & $\begin{array}{l}\text { Ice volume } / 10^{3} \\
\mathrm{~km}^{3}\end{array}$ & $\begin{array}{l}\text { Surface air } \\
\text { temperature } /{ }^{\circ} \mathrm{C}\end{array}$ & $\begin{array}{l}\text { Precipitation / } \\
\text { mm/year }\end{array}$ & $\begin{array}{l}\text { Mixed layer } \\
\text { temperature } /{ }^{\circ} \mathrm{C}\end{array}$ \\
\hline THC-QUMP & $10.8 \pm 0.29$ & $14.5 \pm 6.41$ & $-14.03 \pm 2.48$ & $315.0 \pm 31.0$ & $-0.07 \pm 0.04$ \\
\hline (parameter uncertainty) & $3 \%$ & $44 \%$ & & $10 \%$ & \\
\hline THC-QUMP & \pm 0.11 & \pm 0.33 & \pm 0.18 & \pm 3.3 & \pm 0.01 \\
\hline $\begin{array}{l}\text { Contribution from internal } \\
\text { variability, } \sigma_{\mathbf{v}}\end{array}$ & $37 \%$ & $5 \%$ & $7 \%$ & $11 \%$ & $18 \%$ \\
\hline CMIP3 & $10.68 \pm 0.63$ & $19.65 \pm 9.21$ & $-15.88 \pm 2.38$ & $278 \pm 46$ & $-1.09 \pm 0.44$ \\
\hline (structural and parameter uncertainty) & $6 \%$ & $47 \%$ & & $24 \%$ & \\
\hline CMIP3 & \pm 0.03 & \pm 0.26 & \pm 0.13 & \pm 2.6 & \pm 0.01 \\
\hline $\begin{array}{l}\text { Contribution from internal } \\
\text { variability, } \sigma_{\mathbf{v}}\end{array}$ & $5 \%$ & $3 \%$ & $5 \%$ & $6 \%$ & $3 \%$ \\
\hline Observations & $10.1^{\mathbf{a}}$ & $29.0^{\mathbf{b}}$ & $-8.62^{\mathrm{c}}$ & $234^{\mathrm{d}}$ & N/A \\
\hline
\end{tabular}

Row 1 shows the THC-QUMP ensemble-mean time-mean of years 61-80 from each control integration (Control) together with a measure of the ensemble spread ( \pm one standard deviation of the time-means). Numbers in bold show the ensemble spread as a fraction of the ensemble mean, expressed as a percentage (temperature is excluded since the the zero on the Celsius scale is arbitrary). Row 2 The estimated contribution from internal variability (3). Numbers in italics show internal variability as a percentage of the ensemble spread. Row 3 (4) —as row 1 (2), but for CMIP3 Row 5-observational estimates. For more details see Sect. 6.1

Table 8 Change and Spread of key Arctic variables at double pre-industrial $\mathrm{CO}_{2}$ concentration

\begin{tabular}{|c|c|c|c|c|c|c|c|}
\hline Ensemble & $\begin{array}{l}\text { Ice extent / } \\
10^{6} \mathrm{~km}^{2}\end{array}$ & $\begin{array}{l}\text { Ice volume/ } \\
10^{3} \mathrm{~km}^{3}\end{array}$ & $\begin{array}{l}\text { Surface air } \\
\text { temperature } \\
{ }^{\circ} \mathrm{C}\end{array}$ & $\begin{array}{l}\text { Precipitation } \\
/ \mathrm{mm} / \text { year }\end{array}$ & $\begin{array}{l}\text { Mixed layer } \\
\text { temperature } \\
{ }^{\circ} \mathrm{C}\end{array}$ & $\begin{array}{l}\text { Polar } \\
\text { amplification } \\
\text { of SAT }\end{array}$ & $\begin{array}{l}\text { Polar } \\
\text { amplification } \\
\text { of MLT }\end{array}$ \\
\hline THC-QUMP & $-0.57 \pm 0.23$ & $5.77 \pm 3.17$ & $4.26 \pm 0.63$ & $54 \pm 11$ & $0.67 \pm 0.26$ & $2.25 \pm 0.22$ & $0.42 \pm 0.14$ \\
\hline (Parameter uncertainty) & $40 \%$ & $55 \%$ & $15 \%$ & $21 \%$ & $39 \%$ & $10 \%$ & $33 \%$ \\
\hline THC-QUMP & \pm 0.15 & \pm 0.46 & \pm 0.25 & \pm 4.67 & \pm 0.01 & & \\
\hline $\begin{array}{l}\text { Contribution from } \\
\text { internal variability, } \sigma_{\mathbf{v}}\end{array}$ & $67 \%$ & $14 \%$ & $39 \%$ & $42 \%$ & $5 \%$ & N/A & $N / A$ \\
\hline CMIP3 & $-0.43 \pm 0.21$ & $-8.49 \pm 4.18$ & $4.01 \pm 1.12$ & $53 \pm 17$ & $0.48 \pm 0.36$ & $2.12 \pm 0.39$ & $0.38 \pm 0.20$ \\
\hline $\begin{array}{l}\text { (structural and parameter } \\
\text { uncertainty) }\end{array}$ & $48 \%$ & $49 \%$ & $28 \%$ & $32 \%$ & $75 \%$ & $18 \%$ & $53 \%$ \\
\hline CMIP3 & \pm 0.04 & \pm 0.37 & \pm 0.18 & \pm 3.7 & \pm 0.02 & & \\
\hline $\begin{array}{l}\text { Contribution from } \\
\text { internal variability, } \sigma_{\mathbf{v}}\end{array}$ & $20 \%$ & $9 \%$ & $16 \%$ & $22 \%$ & $6 \%$ & N/A & N/A \\
\hline
\end{tabular}

As Table 7, but for $2 \times \mathrm{CO}_{2}-$ Control: the difference between the time-mean of the $2 \times \mathrm{CO}_{2}$ experiment and the time-mean of the control integration, for years 61:80- the 20 years centred on the $\mathrm{CO}_{2}$ doubling time. See Sect. 6.1 for more details

is partly responsible for the spread (hence uncertainty) in projections of Arctic climate change.

To determine the relationship of the spread in the climatologies with the spread in the projected changes under a doubling of $\mathrm{CO}_{2}$ we look at the correlations across each ensemble. For example, Fig. 4 a shows the change in sea ice volume at the $\mathrm{CO}_{2}$ doubling time, against the sea ice volume climatology in the control integration, for each model in the CMIP3 ensemble. There is a clear negative relationship between the initial volume of sea ice (climatology) and the magnitude of the change in sea ice volume at $\mathrm{CO}_{2}$ doubling as first noted by Holland et al. (2010). That is, the ice volume at the start of the $2 \times \mathrm{CO}_{2}$ experiment, determines, in a large part, the magnitude of the sea ice volume reduction upon $\mathrm{CO}_{2}$ doubling. This behaviour could arise if a significant number of models were free of sea ice by $\mathrm{CO}_{2}$ doubling (hence the volume change would only be dependent on mean volume in the control). To test this we reexamine the relationship in September (the summer sea ice minimum) sea ice volumes half-way through the $\mathrm{CO}_{2}$ doubling experiment (Fig. 4b) - here we have explicitly excluded two models where the sea ice volumes fall below $10^{3} \mathrm{~km}^{3}$ by $\mathrm{CO}_{2}$ doubling (years $60-79$ ) to exclude sea-ice free conditions. The relationship is even stronger-suggesting that the effect is real.

To further examine the dependence of Arctic climate change on the spread of model climatologies we repeat this correlation analysis for the change in seven key Arctic 

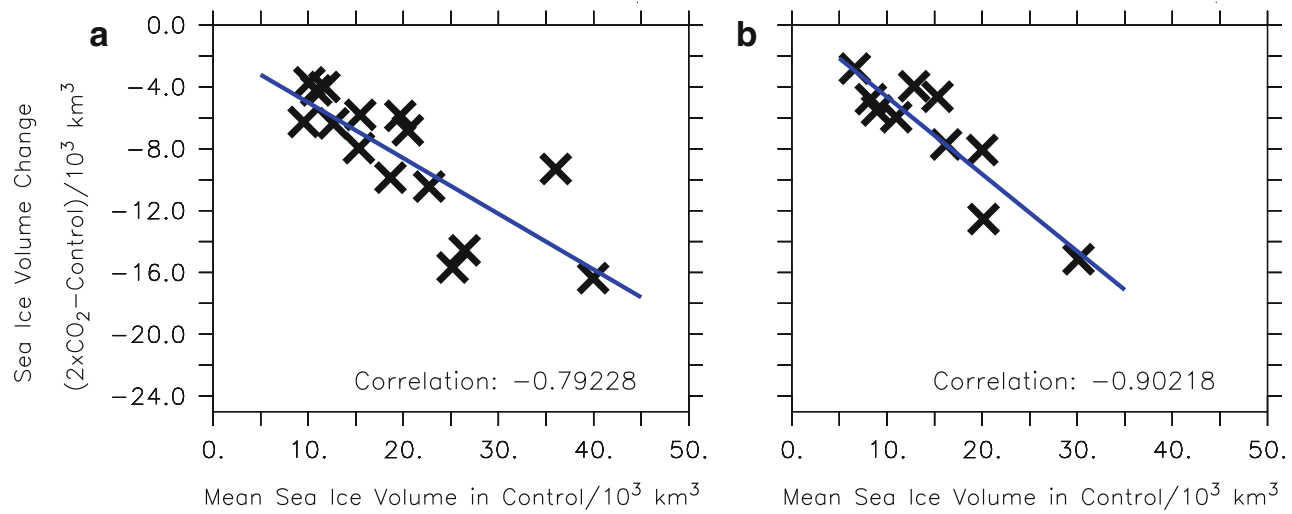

Fig. 4 a The relationship between the projected changes in annual mean sea ice volume under $\mathrm{CO}_{2}$ doubling and the climatology of the annual mean sea ice volume for all models in the CMIP3 ensemble. The correlation is -0.79 . See also Holland et al. (2010). b as a But

variables (as in Table 8) and their relation to a range of quantities in the control climatology (means of years 61-80 in the control integrations). The results are presented for both ensembles in Table 9. There are clear similarities and differences between the two ensembles. The large (negative) correlations between sea ice volume climatology (in the Control integration) and the sea ice volume change are clearly seen in both ensembles.

As noted previously THC-QUMP ensemble differ in the values of certain parameters within key model parameterizations. The similarity of the correlation of the sea ice volume change and climatology between the two ensembles suggest that the relationship is fundamentally related to parameter uncertainty. Figure 5 shows the variation of the sea ice volume climatology (in the THCQUMP control integration) as one of the model parameters varies: Ice albedo at $0{ }^{\circ} \mathrm{C}$. The dataset is limited but ice volumes are significantly different $(p<0.03)$ between upper and lower albedo ranges. Taken together with the result that sea ice volume changes are negatively correlated with sea ice volumes in the control (Table 9), this may suggest that sea ice volume changes under a doubling of $\mathrm{CO}_{2}$ are directly related to the value of parameters contained within the sea ice albedo parameterization. Hence uncertainty in sea ice volume projections may be explained, in part, by the uncertainty in the sea ice albedo parameterization schemes. Physically this could arise because the surface albedo controls the climatological radiation balance within the region, and hence the ice energy budget and thus the climatological ice volume. Once thick sea ice is established, the top surface of the ice becomes well-insulated from the cold ocean underneath the ice $\left(-1.8{ }^{\circ} \mathrm{C}\right.$ for freezing seawater). This may allow the top surface of the ice to melt in response to a given surface heat flux, whereas a thinner ice-in closer thermal contact with a cold ocean 'buffer'-would not. for September sea ice volume (years 40-59) — for all models except for two where the sea ice volume drops below $10^{3} \mathrm{~km}^{3}$ in years 60-79. Correlation: -0.90

Hence explaining the greater sea ice loss in the models with greater initial sea ice volumes.

Examination of Table 9 reveals a number of other interesting relationships. In the CMIP3 ensemble, the northward ocean heat transport in the Control integration climatology is significantly correlated with changes in five of the seven Arctic variables. Some of these relationships can be seen more clearly in Fig. 6 where they are plotted together with the data for Atlantic only ocean heat transport (where available). These suggest that the climatology of the model ocean heat transport into the Arctic explains a substantial part of the spread (uncertainty) in key aspects of Arctic climate change (surface air temperature, precipitation, mixed layer temperatures and sea ice extent).

A similar relationship between surface air temperature and the climatology of the model ocean heat transport into the Arctic has also recently been documented in the A1B scenario experiments (Mahlstein and Knutti 2010). It is interesting to note that the correlation between sea ice volume changes and Atlantic Ocean Heat transport are the opposite sign to the correlation between sea ice extent and Atlantic Ocean Heat transport, although the former is not statistically significant. This opposition of signs persists even if we consider all northern hemisphere ice $(0: 90 \mathrm{~N})$ rather that that within our Arctic definition (70:90N).

These relationships are entirely absent from the THCQUMP ensemble. This may suggest that this dependence is due to structural uncertainty, rather than parameter uncertainty. A study by Jackson et al. (2011) reveals that the spread of MOC strengths in THC-QUMP is less than that of the CMIP3 ensemble, with most THC-QUMP ensemble members having an MOC strength within the observational range. It is important to note that the model parameters that were varied to create the THC-QUMP ensemble were not chosen specifically to cause a spread in ocean heat transports-no ocean dynamics parameters 
Table 9 Correlations between changes in Arctic variables $\left(2 \times \mathrm{CO}_{2}-\right.$ Control: columns $)$ and a variable in the control integration climatology (Control: rows) (left:CMIP3, right:THC-QUMP)

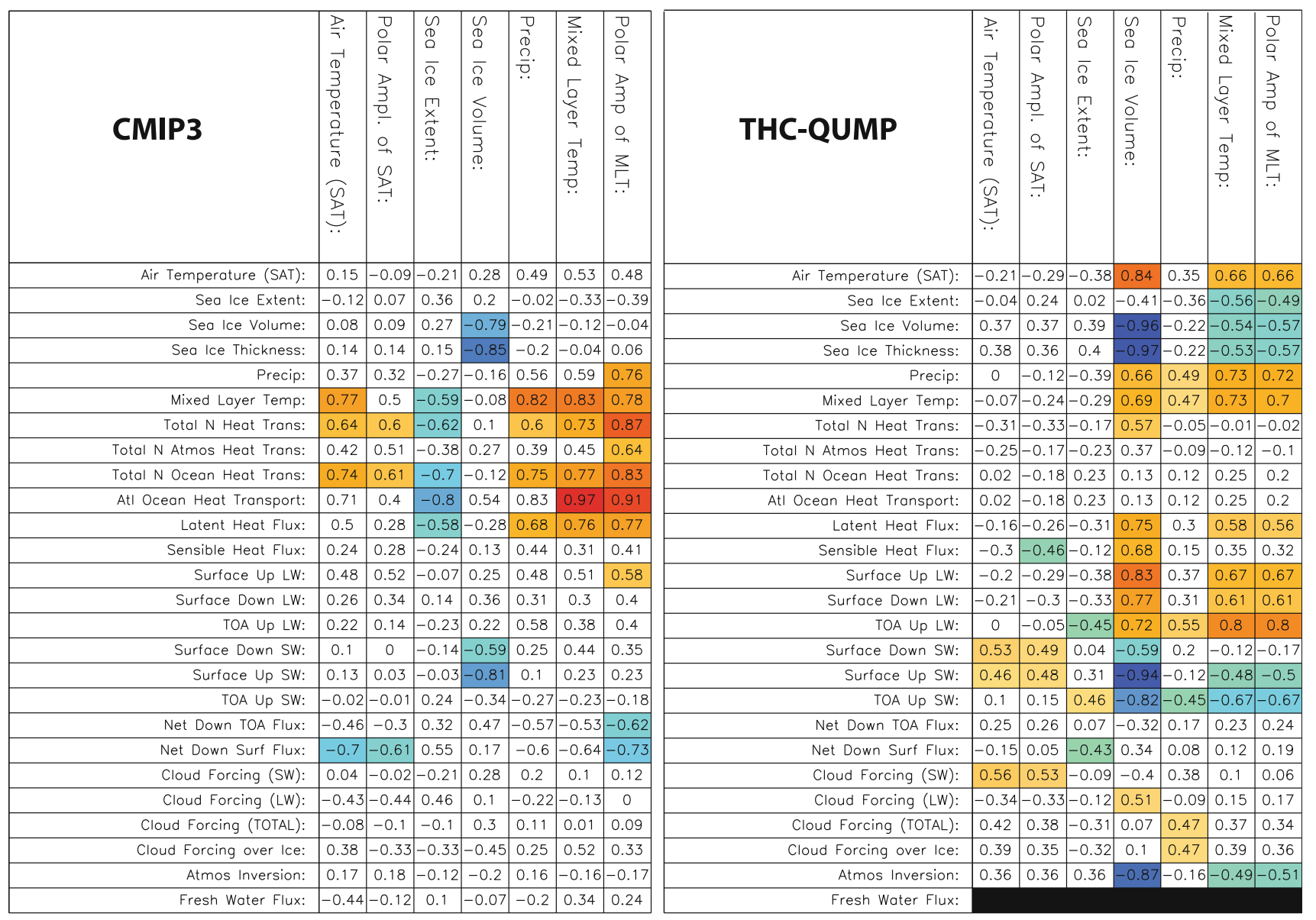

Coefficients in a coloured box are significant $(p<0.05)$ for the ensemble size, with blue (red) indicating a negative (positive) correlation. Variables are defined in Sect. 6.2. Some models are missing some variables in the CMIP3 archive-hence the CMIP3 ensemble size is not always the same size for each variable. Consequently the sample size varies and hence so does the magnitude correlation required for a significant value. The number of models used ranges from 6 to 18

were perturbed, for example (see Table 6)—hence they may under-sample any parameter uncertainty that exists. Hence, the lack of these relationships in the THC-QUMP table may be because these rely on the interaction of the spread in ocean heat transport and sea ice volume-an interaction that does not occur in the THC-QUMP ensemble.

The THC-QUMP ensemble does show a strong positive correlation between the control climatological surface air temperature and sea ice volume change. However, this is likely due to the link between control climatological sea ice volume and temperature. Higher temperatures in the control will be accompanied by a lower volume of sea ice. As noted previously, models with lower initial ice volumes result in smaller ice volume changes under $2 \times \mathrm{CO}^{2}$. Such changes are always negative (a reduction) in a warming climate, hence higher temperatures are related to smaller negative changes in ice volume. Therefore we would expect a positive correlation between control SAT and sea ice volume.

Similarly, we expect that many of the other significant correlations in the THC-QUMP ensemble are related to the spread in sea ice volume climatologies (for example: Shortwave (SW) flux at the top of the atmosphere (TOA Up SW)-High sea ice volumes are likely to have high sea ice coverage, increasing the upward top of the atmosphere flux in the shortwave band. High sea ice coverage results in less heat being stored in the mixed layer during summerhence lower annual mean mixed layer temperatures).

The result shown in Fig. 5 and Table 9 imply that reductions in the spread in Arctic model climatologies are an important step in reducing uncertainty in future Arctic climate projections. Figure 5 suggests that for ice volume this uncertainty may be reduced by better constraining the 
ice albedo parameter in model parameterizations (although this may reveal underlying structural uncertainties-see Sect. 2). Furthermore, Table 9 shows the importance of a

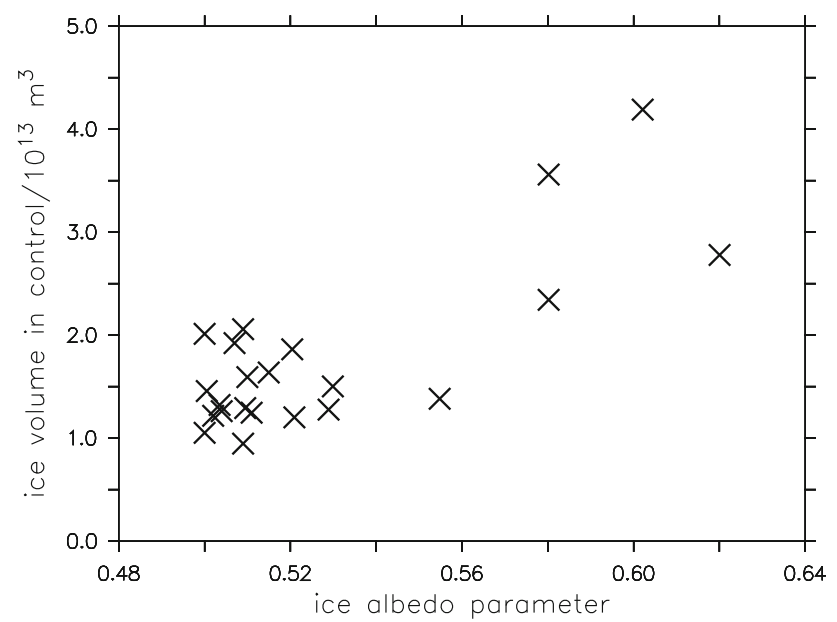

Fig. 5 The variation of sea ice volume climatology and variations in the albedo parameter in the QUMP ensemble. The ice volumes in the upper half of the albedo range (0.56-0.62) are significantly different $(p<0.03)$ to the ice volumes in the lower half of the albedo range $(0.5-0.56)$
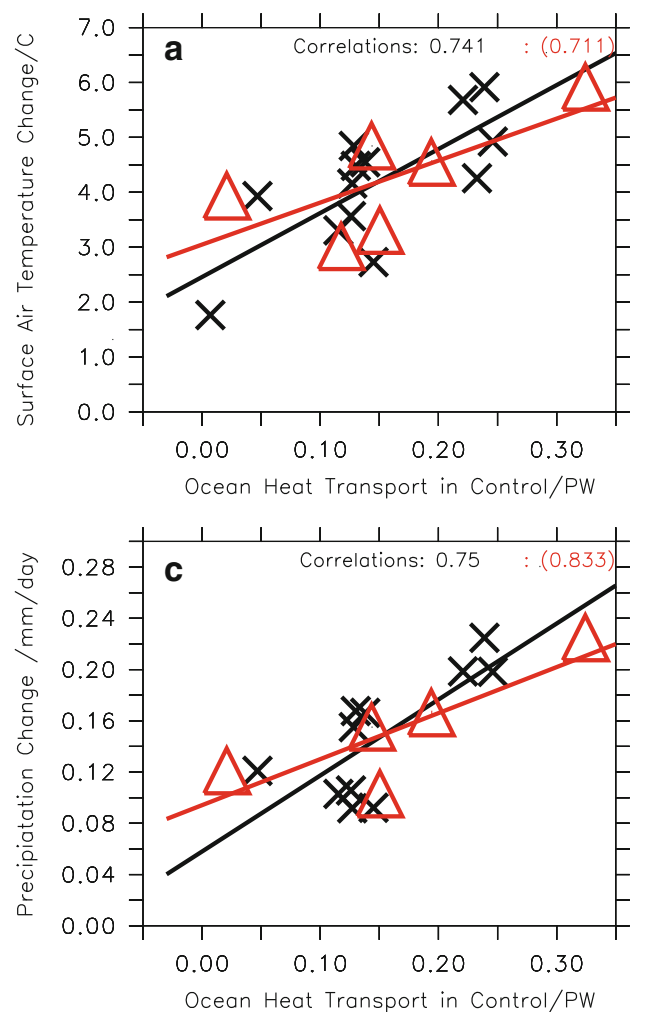

Fig. 6 Relationships between changes $\left(2 \times \mathrm{CO}^{2}-\right.$ Control $)$ in Arctic variables and the time mean Ocean Heat Transport at $70 \mathrm{~N}$ (black: Global (Total N Ocean Heat Trans), red: Atlantic [Atl Ocean Heat Transport)]—across all available models. a Air realistic ocean heat climatology when forming projections of future Arctic climate change.

\section{Conclusions}

The goal of this study is to assess and quantify the uncertainty in current Arctic climate projections in a consistent manner. We have examined the uncertainty (ensemble spread) in the response of Arctic Climate to a doubling of atmospheric $\mathrm{CO}_{2}$ concentrations in both a multimodel ensemble (CMIP3) and a single-model perturbed-parameter ensemble (THC-QUMP).

The range of models used in the CMIP3 ensemble have control climatologies that are generally consistent with historical observations of Arctic climate, although the spread of the climatologies can be quite large, particularly for some quantities (e.g. sea ice volume). Both structural and parameter uncertainties are likely to be significant sources of spread, since the spread of both ensembles (CMIP3 and THC-QUMP) is larger than our estimate of intrinsic climate noise (internal variability)—although further analysis will be required to robustly confirm this (see Sect. 2.4).
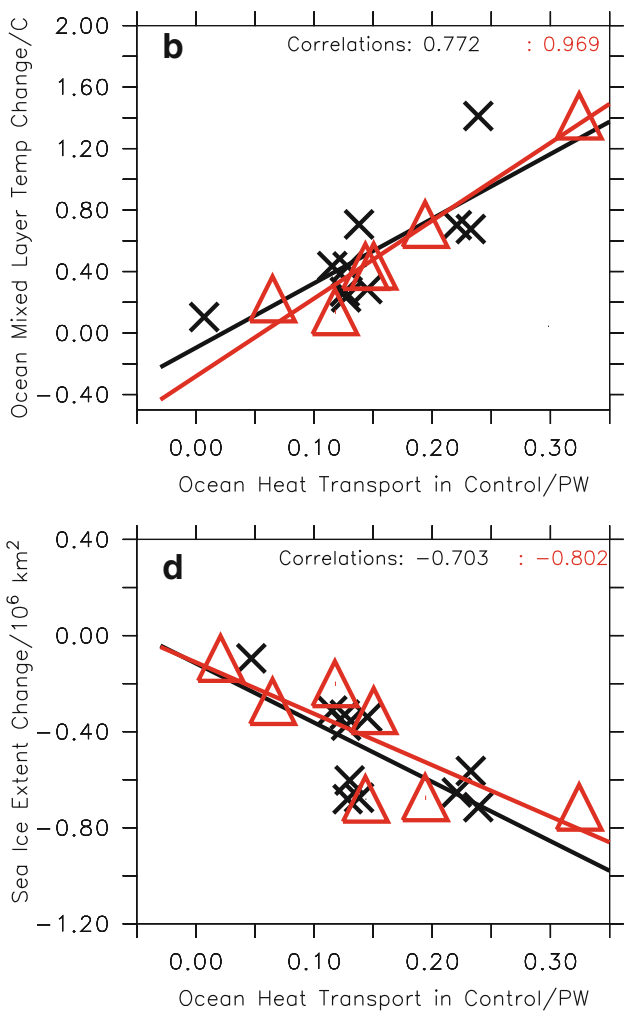

Temperature (SAT), b Mixed Layer Temp, c Precip, d Sea Ice Extent. Correlations that are not significant $(p \geq 0.05)$ are given in brackets. Variables in bold as defined in Sect. 6.2 
The ensemble spread of model climatologies is generally greater for the CMIP3 (multimodel) ensemble than the THC-QUMP (single model, multiple parameter) ensemble. This may suggest that structural uncertainty explains a notable fraction of the ensemble spread. However, although considerable efforts were made to uniformly sample parameter uncertainty (see Sect. 2.2), it is hard to directly relate this to parameter uncertainty within the CMIP3 ensemble

Our key findings from this study are that:

- The uncertainty (ensemble spread) in the projections of changes in many Arctic quantities (e.g sea ice volume, mixed layer temperature) is large $(\sim 30-50 \%)$, when compared to the ensemble mean changes.

- Sub-gridscale parameterizations and model structure variations are likely to be the most significant contributions to this uncertainty, rather than intrinsic internal variability. However, further work sampling internal variability using perturbed initial condition ensembles will be required to robustly test this conclusion (Sect. 2.4).

- Climatological errors (mean state model biases) in both sea ice volume and northward ocean heat transport into the Arctic are critical factors in determining the climate response of the Arctic to a $\mathrm{CO}_{2}$ doubling [these findings mirror studies by Holland et al. (2010) and Mahlstein and Knutti (2010)].

- Such climatological errors in northward ocean heat transport into the Arctic in a model may be ultimately due to structural variations between models (CMIP3) rather than uncertainties in sub-gridscale parameterizations (THC-QUMP).

One limitation of this study is that we have only considered variations in annual means. However, the Arctic is a strongly seasonal climate system driven by the large variation in solar shortwave radiation over the annual cycle. In winter, conditions are often dominated by high surface pressure and strong atmospheric inversion. The resulting heat loss to space leads to sea ice growth and and increased mixed layer depth. In summer, by contrast, the near-permanent sunlight induces surface melting of the sea ice, a well-mixed boundary layer and $90 \%$ cloud cover. Consequently, very different processes determine Arctic climate during summer and winter and model ensemble spread will likely vary with season. We have partly analysed the seasonal dependence in the analysis of shortwave (SW) and longwave (LW) fluxes, both which dominate at different parts of the year-hence capture some of the seasonality. But a full analysis will require seasonally resolved data. Such an analysis may reveal stronger signals in the relationships between processes than we have documented here.
This caveat aside, we have demonstrated that there is considerable uncertainty in climate model projections of Arctic climate and that this uncertainty likely has its origins in model structural and parameter uncertainty, rather than internal variability, although further work with multiple-initial conditions ensembles is required to robustly test this. A large part of this uncertainty results from model biases (inter-model differences in the mean state). Addressing these biases, through technical model improvements together with better constraints on models from improved observations (most notably, heat transports into the Arctic and Arctic sea ice volume), will likely lead to significant reductions in the uncertainty of model projections of future Arctic climate.

Acknowledgments This paper describes part of the work for the Identifying Uncertainties in Arctic Climate Predictions scoping study for the NERC Arctic Research Programme-a joint UK Met OfficeNCAS-Climate project funded by NERC. This work was supported by the Joint DECC/Defra Met Office Hadley Centre Climate Programme (GA01101). Thanks to Jonathan Gregory for help with obtaining the CMIP3 datasets. Thanks to Rob Hine (ECMWF) for help with Fig. 1. Thanks also to two anonymous reviewers for useful comments that helped to improve this paper. The authors wish to acknowledge use of the Ferret program for analysis and graphics in this paper. Ferret is a product of NOAA's Pacific Marine Environmental Laboratory. (Information is available at http://ferret.pmel.noaa.gov/Ferret/).

Open Access This article is distributed under the terms of the Creative Commons Attribution License which permits any use, distribution, and reproduction in any medium, provided the original author(s) and the source are credited.

\section{Appendix}

\section{Notes on Tables 7 and 8}

The variables in Tables 7 and 8 are defined below in Sect. 6.2. Ice extents were computed by taking the mean ice concentration across the whole 20 years (61:90), and then integrating the area with a concentration greater than 0.15 . Computing the 20 year mean of monthly ice extents will produce a different result.

Observations are derived as follows: (a) Computed from Observed sea ice coverage (HadISST) $>70^{\circ} \mathrm{N}$ (http:// hadobs.metoffice.com/hadisst). (b) An estimate created by multiplying the Zhang and Walsh (2006) Figure for extent $\left(1979: 199910.6 \times 10^{6} \mathrm{~km}^{2}\right)$ by the Laxon et al. (2003) estimate of winter time mean ice thickness in the Arctic (1993:2001 $2.73 \mathrm{~m}$ ), hence this should be regarded as an upper bound on the true volume. (c) 1979:1999 Mean of Station observations and Reanalysis values given in Liu et al. (2008). Note Liu et al. define the Arctic as the region bounded by the mean sea ice extent, whereas we choose 
Table 10 Definition of variables used in Table 9

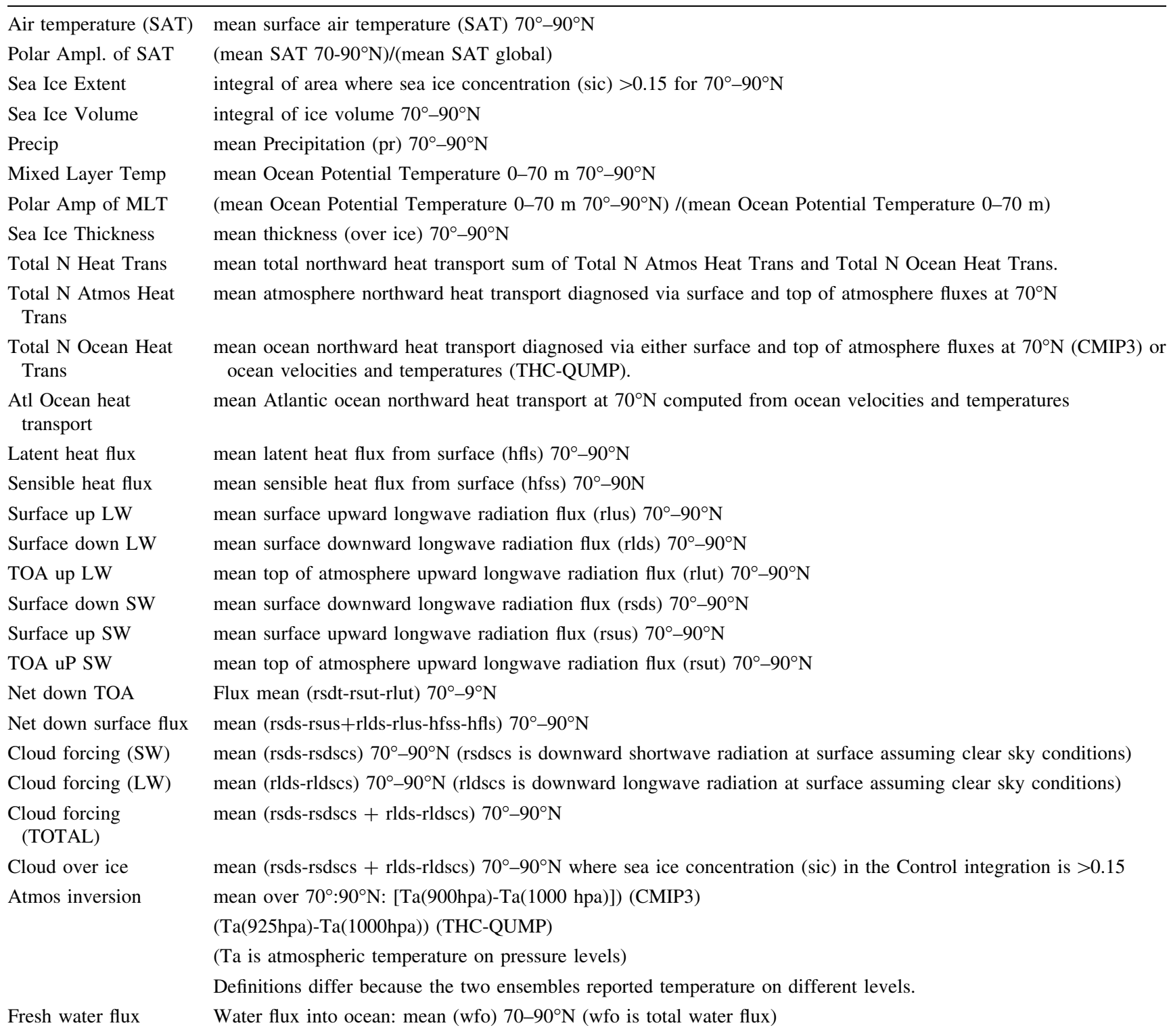

latitudes $>70^{\circ}$ N. (d) Kattsov et al. (2007) (1980:1999) Note: precipitation has been scaled up from $\mathrm{mm} /$ day to $\mathrm{mm} / \mathrm{year}$, in all cases, by multiplying by 360.0 (the number of model days in HadCM3).

\section{Definition of Arctic variables}

See Table 10.

\section{References}

Abbot DS, Walker CC, Tziperman E (2009) Can a convective cloud feedback help to eliminate winter sea ice at high $\mathrm{CO}_{2}$ concentrations? J Clim 22(21):5719-5731. doi:10.1175/2009J CLI2854.1
Bourgain P, Gascard JC (2011) The Arctic Ocean halocline and its interannual variability from 1997 to 2008 . Deep Sea Res I: Oceanogr Res Pap 58(7):745-756. doi:10.1016/j.dsr. 2011.05.001

Chapman WL, Walsh JE (2007) Simulations of arctic temperature and pressure by global coupled models. J Clim 20(4):609-632. doi: 10.1175/JCLI4026.1

Collins WD, Rasch PJ, Boville BA, Hack JJ, McCaa JR, Williamson DL, Briegleb BP, Bitz CM, Lin SJ, Zhang M (2006) The formulation and atmospheric simulation of the community atmosphere model version 3 (cam3). J Clim 19(11):2144-2161

Collins M, Booth B, Bhaskaran B, Harris GR, Murphy JM, Sexton DMH, Webb MJ (2011) Climate models, feedbacks and forcings: a comparison of perturbed-physics and multimodel ensembles. Clim Dyn 36(9):1737-1766. doi:10.1007/s00382010-0808-0

Cubasch U, Boer GM, Stouffer R, Dix M, Noda A, Senior C, Raper S, Abe-Ouchi KY, Brinkop S, Claussen M, Collins M, Evans J, 
Fischer-Bruns I, Flato G, Fyfe J, Ganopolski A, Gregory J, Hu ZZ, Joos F, Knutson T, Knutti R, Landsea C, Mearns L, Milly C, Mitchell J, Nozawa T, Paeth H, Räisänen J, Sausen R, Smith S, Stocker T, Timmermann A, Ulbrich U, Weaver A, Wegner J, Whetton P, Wigley T, Winton M, Zwiers F (2001) Projections of future climate change. In: Climate change 2001: the physical science basis. Contribution of working group I to the third assessment report of the intergovernmental panel on climate change. Cambridge University Press

Curry JA, Schramm JL, Serreze MC, Ebert EE (1995) Water vapour feedback over the Arctic Ocean. J Geophys Res 100(D7):14223-14229. doi:10.1029/95JD00824

Curry JA, Schramm JL, Rossow WB, Randall D (1996) Overview of Arctic cloud and radiation characteristics. J Clim 9(8):17311764. doi:10.1175/1520-0442(1996)009<1731:OOACAR> 2.0.CO;2

Deser C, Knutti R, Solomon S, Philips AS (2012) Communication of the role of natural variability in the future of North American climate. Nat Clim Change (accepted)

Eisenman I, Untersteiner N, Wettlaufer JS (2007) On the reliability of simulated Arctic sea ice in global climate models. Geophys Res Lett 34(10):L10, 501+. doi:10.1029/2007GL029914

Hansen J, Ruedy R, Sato M, Lo K (2010) Global surface temperature change. Rev Geophys 48(4):RG4004+. doi:10.1029/2010 RG000345

Hawkins E, Sutton R (2009) The potential to narrow uncertainty in regional climate predictions. Bull Am Meteor Soc 90(8):10951107. doi:10.1175/2009BAMS2607.1

Hawkins E, Sutton R (2011) The potential to narrow uncertainty in projections of regional precipitation change. Clim Dyn 37(1):407-418. doi:10.1007/s00382-010-0810-6

Hodson DLR, Sutton RT (2008) Exploring multi-model atmospheric GCM ensembles with ANOVA. Clim Dyn 31(7):973-986. doi: 10.1007/s00382-008-0372-z

Hodson D, Keeley S, West A, Ridley J, Hewitt H, Hawkins E (2010) Identifying uncertainties in arctic climate predictions. UK National Environment Research Council special report

Holland M, Serreze M, Stroeve J (2010) The sea ice mass budget of the Arctic and its future change as simulated by coupled climate models. Clim Dyn 34(2):185-200. doi:10.1007/s00382-0080493-4

Jackson LC, Vellinga M, Harris GR (2011) The sensitivity of the meridional overturning circulation to modelling uncertainty in a perturbed physics ensemble without flux adjustment. Clim Dyn 39(1): 277-285. doi:10.1007/s00382-011-1110-5

Kattsov VM, Walsh JE, Chapman WL, Govorkova VA, Pavlova TV, Zhang X (2007) Simulation and projection of Arctic freshwater budget components by the IPCC AR4 global climate models. J Hydrometeorol 8(3):571-589. doi:10.1175/JHM575.1

Lawrence DM, Slater AG, Tomas RA, Holland MM, Deser C (2008) Accelerated Arctic land warming and permafrost degradation during rapid sea ice loss. Geophys Res Lett 35(11):L11, 506+. doi:10.1029/2008GL033985

Laxon S, Peacock N, Smith D (2003) High interannual variability of sea ice thickness in the Arctic region. Nature 425(6961):947-950 doi:10.1038/nature02050

Liu J, Zhang Z, Hu Y, Chen L, Dai Y, Ren X (2008) Assessment of surface air temperature over the Arctic Ocean in reanalysis and IPCC AR4 model simulations with IABP/POLES observations.
J Geophys Res 113(D10):D10,105+. doi:10.1029/2007 JD009380

Mahlstein I, Knutti R (2010) Ocean heat transport as a cause for model uncertainty in projected Arctic warming. J Clim 24(5):1451-1460. doi:10.1175/2010JCLI3713.1

Mahlstein I, Knutti R (2012) September Arctic sea ice predicted to disappear near $2{ }^{\circ} \mathrm{C}$ global warming above present. J Geophys Res 12:D6 D06104. doi:10.1029/2011JD016709

Murphy JM, Sexton DMH, Barnett DN, Jones GS, Webb MJ, Collins M, Stainforth DA (2004) Quantification of modelling uncertainties in a large ensemble of climate change simulations. Nature $430: 768-772$. doi:10.1038/nature02771

Pavelsky TM, Boé T, Hall A, Fetzer EJ (2010) Atmospheric inversion strength over polar oceans in winter regulated by sea ice. Clim Dyn 36(5):945-955. doi:10.1007/s00382-010-0756-8

Randall DA, Wood RA, Bony S, Colman R, Fichefet T, Fyfe J, Kattsov V, Pitman A, Shukla J, Srinivasan J, Stouffer RJ, Sumi A, Taylor KE (2007) Climate Models and Their Evaluation: Climate Change 2007: The Physical Basis. Contribution of Working Group I to the Fourth Assessment Report of the Intergovenrmental Panel on Climate Change, Cambridge University Press, Cambridge

Solomon SDQ, Manning M, Chen Z, Marquis M, Averyt K, Tignor M, Miller H (2007) Climate Change 2007: The Physical Science Basis. Contribution of Working Group I to the Fourth Assessment Report of the Intergovernmental Panel on Climate Change. Cambridge University Press, Cambridge

Stainforth DA, Aina T, Christensen C, Collins M, Faull N, Frame DJ, Kettleborough JA, Knight S, Martin A, Murphy JM, Piani C, Sexton D, Smith LA, Spicer RA, Thorpe AJ, Allen MR (2005) Uncertainty in predictions of the climate response to rising levels of greenhouse gases. Nature 433:403-406. doi:10.1038/nature 03301

Steve V, Waliser D, Schweiger A, Francis J (2009) Simulations of 20th and 21st century Arctic cloud amount in the global climate models assessed in the IPCC AR4. Clim Dyn 33(7):1099-1115. doi:10.1007/s00382-008-0475-6

von Storch H, Zwiers FW (2002) Statistical analysis in climate research. Cambridge University Press, ISBN: 0521012309

Symon C, Arris L, Heal B (eds) (2005) ACIA, 2005. Arctic climate impact assessment. Cambridge University Press, Cambridge, chap 9

Vavrus S, Waliser D, Schweiger A, Francis J (2009) Simulations of 20th and 21st century Arctic cloud amount in the global climate models assessed in the IPCC AR4. Clim Dyn 33(7):1099-1115. doi:10.1007/s00382-008-0475-6

Vellinga M, Wu P (2008) Relations between Northward Ocean and atmosphere energy transports in a coupled climate model. J Clim 21(3): 561-575. doi:10.1175/2007JCLI1754.1

Winton M (2006) Surface Albedo feedback estimates for the AR4 climate models. J Clim 19:359-365. doi:10.1175/JCLI3624.1

Yip S, Ferro CAT, Stephenson DB, Hawkins E (2011) A simple, Coherent framework for partitioning uncertainty in climate predictions. J Clim 24(17):4634-4643. doi:10.1175/2011 JCLI4085.1

Zhang X, Walsh JE (2006) Toward a seasonally ice-covered Arctic Ocean: scenarios from the IPCC AR4 model simulations. J Clim 19(9):1730-1747. doi:10.1175/JCLI3767.1 